\title{
Minimal interventions in the teaching of mathematics
}

\author{
Colin Foster \\ School of Education, University of Nottingham, Nottingham, UK \\ For correspondence: colin.foster@nottingham.ac.uk
}

\begin{abstract}
:
This paper addresses ways in which mathematics pedagogy can benefit from insights gleaned from counselling. Person-centred counselling stresses the value of genuineness, warm empathetic listening and minimal intervention to support people in solving their own problems and developing increased autonomy. Such an approach contrasts starkly with the much more directive and leading interventions often made by mathematics teachers in the classroom. In this position paper I argue that minimal teacher interventions are a powerful way to support students in their learning of mathematics. Drawing on the interplay between a mathematics teacher's responsibility to teach mathematics and their duty to support students pastorally, I argue that such an approach builds on skills that teachers already possess and has considerable potential to enhance students' healthy mathematical development.
\end{abstract}

Keywords: Counselling; Learned helplessness; Mathematics teaching; Pastoral care; Student autonomy; Teacher interventions

\section{Introduction}

The journey I wish to describe in this paper began with an incident that happened several years ago when I was teaching a mathematics lesson. A 13-year-old student asked if he could talk to me afterwards about 'a problem'. He seemed relaxed about it, and I naturally assumed that it was a mathematical problem of some kind. As the class were leaving at the end, he waited behind to speak to me, but when I asked him about the problem he said that he wanted to wait until everyone else had gone. This immediately switched me into prepared-for-anything pastoral mode, but once the last person had exited he picked up the board pen and began telling me with enthusiasm about some mathematical puzzles that he had been thinking about. When he paused for breath, I asked him why he hadn't wanted to talk about this with the others around, supposing that he was perhaps embarrassed about displaying his interest in mathematics to his peers. But he explained that he had a plan of presenting some of these puzzles to the rest of the class in a subsequent lesson and did not want them to know the solutions.

My expectations and assumptions were challenged repeatedly during this incident, darting back and forth between 'mathematics' and 'pastoral', and it was interesting to me to consider the unease that I experienced regarding the nature of this student's 'problem'. Preparing myself to expect a mathematical problem felt very different from preparing myself for a personal problem, and it caused me to question the extent to which it was helpful that there should be these two 'me's as a teacher - or this rigid distinction between categories of student enquiry.

Comparing a typical mathematical enquiry, such as 'I'm really confused about quadratic equations', with a pastoral one, such as 'I'm really confused about my sexuality', it becomes apparent that very different ways of responding might be normative, even for the same teacher. A mathematics teacher might respond to the first question by talking and telling, with minimal 'gaps into which students can insert responses' (Francis, 2002, p. 29). The idea of doing the same thing in the second case would be unthinkable, and even the most pastorally-inept teacher would recognise the necessity of listening 
non-judgmentally and giving the student plenty of time to talk. But is this not perhaps also valuable in the mathematical case too?

Table 1. Pastoral and traditional modes contrasted

\begin{tabular}{ll} 
Pastoral mode & Traditional mode \\
\hline mainly listening & mainly talking \\
asking questions & making statements \\
examining multiple possibilities & focusing on a single direction \\
taking time (patience) & hurrying (impatience) \\
likely to involve colleagues & unlikely to involve colleagues \\
normally private & may be public or private \\
teacher feelings of anxiety/uncertainty & teacher feelings of confidence/certainty
\end{tabular}

I have outlined in Table 1 some possible stereotypical contrasts between the sorts of teacher behaviours that might be seen in pastoral or traditional modes. In this paper I consider ways in which mathematics pedagogy might benefit from insights gleaned from counselling. Person-centred counselling values empathy and attentive listening in supporting people to solve their own problems. Such an approach contrasts starkly with the much more directive and leading interventions often made by teachers in the mathematics classroom. I will argue that minimal teacher interventions, in particular, are a powerful way to support students in their learning of mathematics. Drawing on the interplay between a mathematics teacher's responsibility to teach mathematics and their duty to support students pastorally, I will argue that such an approach builds on skills that mathematics teachers already possess and has considerable potential to enhance students' healthy mathematical development.

While working as a school mathematics teacher, I attended a counselling course which I hoped would assist me in being of greater pastoral use to the students in my school. However, I soon became aware that the insights that I was gaining were influencing my mathematics teaching in ways that I regarded as positive, and I began to make notes of situations in which adopting a 'counselling' manner seemed to support students in their learning of mathematics in surprising ways. I will draw on some of these accounts in this paper. I have assembled this paper over a period of more than two years, writing most of it in my classroom during lunchtimes, with students coming in and out, talking to me and asking me to do things for them. Sometimes I have stopped writing to deal with a pastoral problem. This has felt a very different experience from writing a paper in the seclusion of my study. Some of the same students I have worked with pastorally I have also taught mathematics to, and I have increasingly sought to adopt a similar approach in both settings, so that 'it is still me'.

\section{Pastoral versus traditional modes}

The mathematics teacher committed to a constructivist perspective on teaching and learning (von Glasersfeld, 1995) faces a dilemma with regard to the nature and purpose of their interventions in the classroom. On the one hand, frequent heavy interventions while students are working on mathematics risk interrupting their flow and depriving them of the necessary space in which to sustain ownership over the mathematics and make autonomous decisions. On the other hand, for the teacher to adopt a 'facilitating' role that operates merely as an administrative manager of the classroom ('Does anyone need any more paper?') is to fail to do justice to the mathematical and pedagogical knowledge they might bring to bear - and may simply leave other students to fulfil the role of 'transmission teacher' that the 'real' teacher has vacated. Edwards and Mercer (1987, p. 126) describe the teacher's dilemma as 'to have to inculcate knowledge while apparently eliciting it' and, in a similar way, Baxter and Williams $(2010$, p. 8) refer to the 'dilemma of telling' as 'how to facilitate students coming to certain understandings, without directly telling them what they need to know or to do'. The mathematics teacher inevitably has particular intentions but does not want to impose these in a heavy-handed way, and Tahta (1981) makes a distinction between the 'outer task', which the learner is explicitly asked to do, and the 'inner task', which the teacher really hopes they will encounter while doing it. 
In many respects, this dilemma parallels that of the counsellor who desires to support change in their client without disempowering them by assuming excessive responsibility for their life choices. Person-centred counselling, originating in the work of Carl Rogers (1980, 2002, 2007), values genuineness, warm empathic listening and minimal intervention to support people in solving their own problems and developing increased autonomy. A positive life outcome might nevertheless be criticised if it came about as the result of a direct injunction given by the counsellor. Instead of giving direct advice, a person-centred counsellor will tend to look to the client to take responsibility for ideas and decisions.

Such an approach contrasts starkly with 'teacher lust' in the classroom, the desire to tell things to students rather than allow them the space to work them out for themselves (Boole, 1931; Tyminski, 2010). Pratt (2006) found that the more that teachers explained things the more children believed that they would continue to do so, and an excessively authoritarian teacher or counsellor can dangerously de-skill the student or client and generate a debilitating 'learned helplessness' (Peterson, Maier and Seligman, 1995), leading to a lack of mathematical resilience (Johnston-Wilder and Lee, 2010). Bruner (1966) comments on the need for techniques that make a student or problem solver self-sufficient:

Any regimen of correction carries the danger that the learner may become permanently dependent upon the tutor's correction. The tutor must correct the learner in a fashion that eventually makes it possible for the learner to take over the corrective function himself. Otherwise the result of instruction is to create a form of mastery that is contingent upon the perpetual presence of a teacher. (p. 53)

By 'path-smoothing' the student's progress for them (Wigley, 1992), the mathematics teacher may inadvertently inculcate a dependency relationship. Mason's (2000, p. 101) maxim that we should 'only do for people what they cannot yet do for themselves' has much to commend it.

In many UK schools, teachers are expected to assume formal pastoral responsibility for a specific group of students and, even when this is not the case, teaching is widely seen as one of the "caring professions', where concern for social and personal aspects of the student is fundamental (Noddings, 2003, McCloskey, 2012). Teachers may see their didactic and pastoral roles as drawing on very different sets of skills (McLaughlin, Clark and Chisholm, 1996), and consequently attempt to compartmentalise their 'teaching selves'. Indeed, this may be particularly the case for teachers with a subject specialism in the 'hard' sciences or mathematics, where their subject is frequently portrayed as dealing in black-and-white certainties rather than the greys of the humanities (Ernest, 1999). Nonetheless, I argue that mathematics pedagogy has much to learn from pastoral approaches to dealing with students and that this does not require a radical re-skilling of the profession, since the ways of working needed are already implicit in mathematics teachers' pastoral expertise.

\section{Minimal intervention}

The key feature of a pastorally-sensitive and counselling-informed approach that I wish to highlight is 'minimal intervention'. I take a teacher intervention to be 'minimal' if, while engaging empathically in a one-to-one teacher-student situation, it avoids injecting new ideas, leading questions or suggestions from the teacher. Of course, it is necessary for a sensible notion of minimal intervention that the teacher is socially engaged with the student, otherwise any teacher inaction, such as staring out of the window, would qualify as a minimal intervention! Thus, the emphasis on minimal intervention is not to advocate the teacher absenting themselves from the classroom or to say that 'less is more' in a simplistic sense; the approach involves being fully present, interested, engaged, listening, accepting while actively avoiding committing ideas to the learning process.

While teacher interventions are fundamental to a great deal of research in mathematics education, the issue of minimising the intervention has been little studied. Hewitt (1994, p. 206) describes 'the principle of economy' as minimising 'the personal effort and time a student is required to provide in the learning process', basing his insights on 'the productive way students worked when they were very young'. This paper takes a complementary perspective in focusing on the teacher's attempts at economy in minimising the intrusiveness of their classroom presence and interventions. 
The notion of minimal intervention is important in behaviour management (Rogers, 2003), where teachers may be advised to respond to unwanted student behaviour with strategies that begin with less intrusive actions, such as tactical ignoring or brief eye contact, gradually working up to the most draconian measures, such as detentions, only when absolutely necessary and less extreme measures have failed. Outside education, advocates of minimal intervention go back at least as far as the Hippocratic principle of 'do no harm' (Hippocrates, Epidemics, Book I, Section XI). In medicine, a doctor will generally avoid prescribing drugs or procedures when the body's natural healing process is likely to achieve the same result if left alone. Even when decisive and dramatic action is sometimes necessary, less invasive procedures would be generally preferred (Gawande, 2003). There is a cautiousness about unnecessary interference in a complex system such as the human body, and, in a like manner, the mathematics teacher is faced with the delicacy of interfering with students' thinking, and similar reservations might be relevant.

An extremely important contribution to research on actively minimising interventions has emerged from the founding of nondirective client-centred therapy by Carl Rogers in the 1950s (Rogers, 1980, 2002 , 2007). This highly influential humanistic approach to counselling moved away from attempts to push people in particular 'helpful' directions and instead was founded on Rogers' belief (1980) that people contain within themselves the capacity to handle their own problems if they can learn to trust themselves to do so:

I have come to trust the capacity of persons to explore and understand themselves and their troubles, and to resolve those problems, in any close, continuing relationship where I can provide a climate of real warmth and understanding. (p. 38)

Solutions could not be prescribed, like medicine; instead, Rogers would seek to describe his feelings in the moment and what he understood the client to be saying. Above everything, Rogers (1980) prized genuineness and empathy:

A high degree of empathy in the therapeutic relationship is associated with various aspects of process and progress in the therapy ... The degree of empathy that exists ... [is] predictive of the later success or lack of success in therapy. (pp. 146-147)

All of Rogers' writings describe the same approach, whether it is with patients, colleagues, students, family members, business colleagues or political leaders (Rogers, 1980, 2002, 2007). Rogers was greatly interested in non-pathological applications of the person-centred approach outside psychotherapy, including education, and Cornelius-White (2007, p. 114) comments that 'Rogers' theory of education has as its goal the facilitation of the whole and fully functioning person, who is a citizen and leader in a democratic society.' Regarding teaching, Rogers (1980) felt sure that the transformational effect of empathy:

would hold in the classroom world as well. If we measured the teacher's attitudes during the first five days of the school year ... we could predict which classrooms would contain learners, and which would contain prisoners. (p. 277)

Indeed, despite the considerable differences between the counsellor's couch and a school classroom, Rogers and Freiberg (1994) remark that:

When the teacher has the ability to understand the student's reactions from the inside, has a sensitive awareness of the way the process of education and learning seems to the student, then ... the likelihood of significant learning is increased. This kind of understanding is sharply different from the usual evaluative understanding, which follows the pattern 'I understand what is wrong with you' ... This attitude of standing in the other person's shoes, of viewing the world through the student's eyes, is almost unheard of in the classroom. (pp. 157-158)

'Minimal intervention' might be regarded as something of a misnomer, since, far from being masterly inaction, it requires considerable thought and takes time to develop. Empathic listening is hard because, as Rogers (2002, p. 18) points out, evaluating gets in the way: 'Our first reaction to most of the statements which we hear from other people is an immediate evaluation, or judgment, rather than an understanding of it'. As Gordon (1951) puts it:

Apparently the act of attending carefully to another person is a difficult task for most people. They are usually thinking what they will say when the speaker stops. Or they focus on some specific point made by the speaker and then fail to attend to the rest because they are thinking up arguments against the specific point. (p. 349) 
Thus, the major difficulty in implementing a minimal intervention approach in the mathematics classroom is the teacher's difficulty in diverting their 'yes, but's and attending to the student on their own terms. Coles (2002) describes 'transformative listening' as going beyond 'interpretive listening' in being 'open to the interrogation of assumptions I am making' (p. 24), and the teacher who listens transformatively is willing to modify their thinking to take into account what the student says.

\section{In the mathematics classroom}

The challenge of applying 'minimal intervention' to the mathematics classroom is a significant one. In order to be less interventionist, it is not enough just to exhort the teacher to 'hold back': the teacher needs to do something with the energy that is wanting to drive them towards a big intervention. Taking a research perspective on the students' learning can be very helpful, so that the teacher's intention switches from 'helping' to 'understanding in depth'. For me, Dewey's (1991) notion of standing back and looking at a problem - being comfortable with sustained uncertainty - has been significant in enabling me to tolerate withholding judgment on what a student is saying. Dewey (1991) describes it as climbing a tree:

Thinking begins in what may fairly enough be called a forked-road situation, a situation which is ambiguous, which presents a dilemma, which proposes alternatives ... In the suspense of uncertainty, we metaphorically climb a tree; we try to find some standpoint from which we may survey additional facts and, getting a more commanding view of the situation, may decide how the facts stand related to one another. (p. 11)

Withholding judgment internally makes it easier for the teacher to refrain from overt evaluative comments, which otherwise tend to leak out through body language even if the teacher is silent. Genuinely not having made your mind up is the safest way to avoid blurting out your point of view.

Another strategy for staying with student uncertainty, rather than trying to resolve it, is to acknowledge it explicitly. For example, when a student asks, 'Is this right?' rather than saying yes or no, or asking them to say what they think - which might rush them to a randomly-selected resolution - I have often responded with 'You're not sure if it's right or not', said in a neutral rather than a questioning way, and followed by a pause. Normally the student then goes on to talk about the mathematics. As they begin to justify whether the mathematics in question is 'right' or not, I might say 'You sound like you're coming round to saying that you think it is right/wrong?' - and I would say this regardless of whether I agreed with their conclusion. My attempt is to reflect back the student's current thinking, rather than to push it forwards. It might seem valueless to simply summarise where the student is, but such minimal interventions do repeatedly seem to enable students to go deeper, as though by labelling and describing where they have reached they then have the security to go further.

The prevalent school discourse of 'moving students on' conflicts strongly with a pastoral approach in which there is a deliberate attempt to allow students to 'climb a tree' and linger. Coles (2002, p. 32) recognises the importance of lingering when he describes 'the articulation of an idea by different students' as a strategy that can result in 'slowing down and opening up discussion'. Many popular classroom strategies seem designed to do the opposite - induce pressure, often time pressure. By seeking to remove pressure to perform, the teacher can plan for more demanding mathematical work, since they can expect that students will not panic and be upset if they cannot immediately see the solution. Hewitt (2009, p. 4) describes children's frustrations when working on mathematics that is 'tantalisingly just out of reach' and describes how the issue for him 'is not to respond to such frustrations by offering something easier which is within their grasp but to support them during these times of frustration'. Dweck's (2000) findings on mind-sets highlight the importance of productive struggle to develop mathematical resilience (Johnston-Wilder and Lee, 2010), and I have found that a relaxed and unhurried manner, as well as saying things like 'Take your time' or 'I'll come back later on and see what you have to say then' can lead to far deeper student thought.

When a student opens a conversation with the teacher with 'I'm so confused about this', I might sit down next to them and say, 'OK. Tell me about your confusion.' Although I come with my own understanding of the mathematics that is confusing them, I attempt to put this to one side and really 
enter into how the student sees it. My focus is on understanding their confusion, not (yet) thinking about how I can help them to resolve it. Frequently I would find that before I had finished trying to make sense of what they were saying, they had already reached some kind of resolution for themselves. Holt (1990, p. 113) recounts a student saying, 'I don't get it' and him replying 'What don't you get?', which he describes as 'a useless question, but one I can't break myself of asking'. Yet, I have frequently used this response and find students generally happy - relieved, even - to talk about what they 'don't get'. In describing the problem in a supportive atmosphere, the student generally finds some kind of resolution of their own.

A particular issue which has become important to me in my own practice, and when working with colleagues, has been the teacher's intrusion into student discussions. Frequently a teacher arrives while students are mid-discussion and immediately interrupts what is being said with words such as 'Right, so how are you getting on then?' In this way, students become habituated into stopping speaking when the teacher arrives, making it hard for the teacher to 'eavesdrop' on student discussions. To reverse this behaviour, I have encouraged teachers to walk up to a group, say nothing - just listen - and then leave. At first, the students stop and look expectantly at the teacher for a question, but if the teacher just smiles, or says something like, 'Please carry on', eventually the teacher can overhear without intruding, and thus make a perhaps more pertinent contribution later. Seeing this happen has been a powerful image for me of the power of minimal intervention.

When I first embarked on this approach, some students were clearly frustrated by my reluctance to answer their questions ('Can't you just tell me?', 'Will you show me how to do it?'), and I found it helpful to explain what I was trying to do by saying things like 'I guess the point is for you to work it out'. Sometimes I would simply reply: 'You'd really like it if I could just tell you how to do it', and this seemed to release some tension. At first I felt that on 'arbitrary' matters (Hewitt, 1999), such as mathematical definitions, I would make an exception to my approach, and reply to simple requests for information with simple answers. However, when I did try not answering even in situations like this, I was frequently surprised that students knew anyway - something that I would not have otherwise discovered:

Student What does 'integer' mean?

Teacher Integer?

Student Yes, is it just a whole number?

It may be that the absolutist nature of commonly-held perceptions of mathematics (Ernest, 1999) sometimes drives teachers towards definite, definitive, explanatory interventions, or it may be that political pressures towards achieving performative goals push teachers generally in this direction. Cotton (1999) comments how a colleague:

noted the difference between her approach to responding to a piece of writing and a piece of mathematics. She described how, when commenting on a story, she always responds personally to the context before remarking on technical matters. She describes her marking of mathematics as 'a series of ticks and crosses which children use to position themselves on a success/failure scale.' (p. 82)

Much one-to-one teacher support of students could be described as either evaluating or giving advice, two things which Rogers strongly counsels against. For example, Rogers (2007) offers a blanket caution against advice giving, which I wish to include in full, since his reasons parallel so much which teachers might identify with in their dealings with students:

The counselor who has made directive suggestions to clients (and what counselor has not?) will perceive the ... grudging, incomplete type of action which follows a direct suggestion, in those cases where the suggestion is not disregarded entirely. In response to direct suggestion and advice the client delays taking action. He carries out part of the suggestion, but not the crucial portion. He carries it out in such a way as to defeat the counselor's purpose. He carries it out halfheartedly, and then reports its failure. All this contrasts very sharply with the type of action taken by the client who has been freed by the counseling situation to a point where he can attain insight and formulate actions in line with his newly chosen goals. Here is no halfheartedness, nor action taken only after prodding. The step is taken in clear-cut fashion. The client is pleased with the results. (pp. 215-6)

If the mathematics teacher believes that they know what the student needs to know and do - they feel that they have seen 'this misconception' a hundred times before - then they are very likely to want to 'pass on' that knowledge, inevitably resulting in advice-giving. Then they will be disappointed when the student forgets or misapplies that advice. 
I have found that repeatedly responding in non-directive ways seems to reduce openings such as 'How do you ...?' and increase the occurrence of student statements rather than overt questions. The students still want to talk to their mathematics teacher, but more so that they can share something ('I've worked it out!', 'This is weird!', 'Can I show you something?'). There is less of an expectation that the teacher will solve their problems or tell them what to do next. Equally, when things are not going well, 'merely' tuning in to a student's frustrations with some mathematics may sometimes be all that is needed.

\section{Conclusion}

Since attempting to adopt a more pastorally-informed approach to teaching mathematics, I have begun to view much mathematics teaching as 'over-teaching', in the sense of 'over-acting' in the theatre. It draws attention to itself in an intrusive and distracting way and does not achieve what it intends. Too much intervention is constricting and disabling for students. Being a nice, friendly listener is not an easy option, and is not necessarily what students want from their teacher especially in the early stages. However, being 'nice' on a personal level is compatible with mathematical toughness, since giving time and space to the student allows the teacher to be much more demanding about the need for rigorous mathematical reasoning. Students can handle being left for longer with something mathematically problematic if they feel personally supported.

Coles (Brown and Coles, 2008) describes a classroom incident involving a 15-16-year-old student in which sensitive listening 'without me saying anything' (p. 24) led to spontaneous progress on the part of the student:

I asked him what had just happened and he replied that all he had done was talk about where he was stuck. I suggested he didn't need me there to do this. About ten minutes later, in which time he had seemingly been very focused, he exclaimed: 'It worked!'. I asked: 'What?' and he replied: 'What you said! I got stuck on this question and talked to myself and worked out what to do!' (p. 24)

This incident captures beautifully for me the way in which students can develop improved metacognitive awareness leading to greater autonomy, so that the scaffolding of the teacher's presence can fade. Just as this is the intention in every counselling situation, it must also be the mathematics teacher's aim.

It is hard to find a suitable metaphor for the teacher's minimal interventionist role. Nolder (1992) cautions against using the term catalyst to indicate an element that participates and assists in a process without being part of the product. Although this might seem like a helpful notion, she points out that an essential feature of a catalyst is that it is unchanged by the process, and the teacher must always be a learner too, and therefore will be transformed by their teaching - they will not emerge unscathed. This very much echoes Rogers' view of how counsellors develop by learning from their clients. Barkham (2011) describes an approach taken to help primary children read aloud called 'a listening dog'. He recounts how the greyhound 'does not criticise or correct their pronunciation. He just nods and pricks up an ear, although sometimes he closes his eyes and appears not to be listening'. No doubt the non-judgmental quality of dogs is part of what makes them such popular pets. The role of the mathematics teacher is envisaged here as considerably more than a passive 'sleeping dog', blissfully unaware of what is going on around. Yet perhaps that image is a helpful one in drawing us away from the model of the over-busy teacher, bustling around the room trying to micromanage every detail of the students' mathematical learning. Attempting to minimise that sort of fussy intervention seems to me extremely worthwhile.

\section{Acknowledgements}

I would like to thank Alf Coles for very helpful comments on previous versions of this paper.

\section{References}

Barkham, P. (2011). The dogs who listen to children reading: Scheme aims to encourage children to read aloud. The Guardian, 28 February, http://www.guardian.co.uk/education/2011/feb/28/dogs-listen-to-children-reading (accessed 23 June 2013). 
Baxter, J. A. and Williams, S. (2010). Social and analytic scaffolding in middle school mathematics: Managing the dilemma of telling. Journal of Mathematics Teacher Education, 13, 7-26.

Boole, M. E. (1931). Teacher-lust. In E. M. Cobham (ed.) Mary Everest Boole: Collected works, volume 4, London: C.W. Daniel, pp. 1411-1413.

Brown, L. and Coles, A. (2008). Hearing Silence: Learning to teach mathematics. London: Black Apollo Press.

Bruner, J. S. (1966). Toward a Theory of Instruction. Cambridge, Mass.: Harvard University Press.

Coles, A. (2002). Teaching strategies related to listening and hearing in two secondary classrooms. Research in Mathematics Education, 4(1), 21-34.

Cornelius-White, J. (2007). Learner-centered teacher-student relationships are effective: A meta-analysis. Review of Educational Research, 77(1), 113-143.

Cotton, T. (1999). 'Flipping the Coin': Models for social justice and the mathematics classroom. In L. Brown (ed.) Making Meanings in Mathematics: A collection of extended and refereed papers from BSRLM - the British Society for Research into Learning Mathematics, Great Britain: QED and BSRLM.

Dewey, J. (1991). How We Think. New York: Prometheus Books.

Dweck, C. S. (2000). Self-Theories: Their role in motivation, personality, and development. Philadelphia: Taylor \& Francis,

Edwards, D. and Mercer, N. (1987). Common Knowledge: The development of understanding in the classroom. London: Methuen.

Ernest, P. (1999). Forms of knowledge in mathematics and mathematics education: Philosophical and rhetorical perspectives. Educational Studies in Mathematics, 38, 67-83.

Francis, P. (2002). Get on with your talk. Secondary English Magazine, 5(4), 28-30.

Gawande, A. (2003). Complications: A surgeon's notes on an imperfect science. London: Profile Books Ltd.

Gordon, T. (1951). Group-centred leadership and administration. In C. R. Rogers (ed.) Client-Centred Therapy. London: Constable.

Hewitt, D. (1994). The Principle of Economy in the Teaching and Learning of Mathematics, unpublished PhD thesis, Milton Keynes: The Open University.

Hewitt, D. (1999). Arbitrary and necessary part 1: A way of viewing the mathematics curriculum. For the Learning of Mathematics, 19(3), 2-9.

Hewitt, D. (2009). From before birth to beginning school. In J. Houssart and J. Mason (eds) Listening Counts: Listening to young learners of mathematics. Stoke-on-Trent: Trentham Books.

Holt, J. (1990). How Children Fail. London: Penguin.

Johnston-Wilder, S. and Lee, C. (2010). Mathematical resilience. Mathematics Teaching, 218, 38-41.

McCloskey, A. (2012). Caring in professional development projects for mathematics teachers: An example of stimulation and harmonizing. For the Learning of Mathematics, 32(3), 28-33.

McLaughlin, C., Clark, P. and Chisholm, M. (1996). Counselling and Guidance in Schools. London: David Fulton Publishers.

Mason, J. (2000). Asking mathematical questions mathematically. International Journal of Mathematical Education in Science and Technology, 31, 97-111.

Noddings, N. (2003). Happiness and Education. Cambridge: Cambridge University Press.

Nolder, R. (1992). Confounding the myth of the catalyst. British Journal of In-Service Education, 18(2), 87-89.

Peterson, C., Maier, S. F. and Seligman, M. E. P. (1995). Learned Helplessness: A theory for the age of personal control. Oxford: Oxford University Press Paperback.

Pratt, N. (2006). 'Interactive' teaching in numeracy lessons: What do children have to say? Cambridge Journal of Education, 36, 221-235.

Rogers, B. (2003). Classroom Behaviour: A practical guide to effective teaching, behaviour management and colleague support. London: Paul Chapman Publishing.

Rogers, C. (1980). A Way of Being. New York: Houghton Mifflin Company.

Rogers, C. (2002). On Becoming a Person: A therapist's view of psychotherapy. London: Constable.

Rogers, C. (2007). Counseling and Psychotherapy. Cambridge, Massachusetts: The Riverside Press.

Rogers, C. R. and Freiberg, H. J. (1994). Freedom to Learn. New Jersey: Prentice Hall Inc.

Tahta, D. (1981) 'Some thoughts arising from the new Nicolet films', Mathematics Teaching, 94, 25-9.

Tyminski, A. (2010). Teacher lust: Reconstructing the construct for mathematics instruction. Journal of Mathematics Teacher Education, 13(4), 295-311.

von Glasersfeld, E. (1995). Radical Constructivism: A way of learning (Studies in mathematics education). London: RoutledgeFalmer. Wigley, A. (1992). Models for teaching mathematics. Mathematics Teaching, 141(4), 7. 